\title{
BMJ Open Assessing the effect of Michigan's smoke-free law on air quality inside restaurants and casinos: a before-and- after observational study
}

\author{
Farid Shamo, ${ }^{1}$ Teri Wilson, ${ }^{1}$ Janet Kiley, ${ }^{1}$ James Repace ${ }^{2}$
}

To cite: Shamo F, Wilson T, Kiley J, et al. Assessing the effect of Michigan's smokefree law on air quality inside restaurants and casinos: a before-and-after observational study. BMJ Open 2015;5: e007530. doi:10.1136/ bmjopen-2014-007530

- Prepublication history for this paper is available online. To view these files please visit the journal online (http://dx.doi.org/10.1136/ bmjopen-2014-007530).

Received 23 December 2014 Revised 12 May 2015 Accepted 14 May 2015

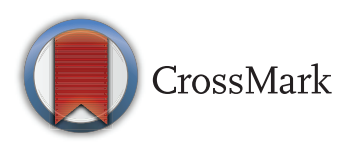

${ }^{1}$ The Michigan Department of Community Health, Division of Chronic Diseases, Lansing, Michigan, USA

${ }^{2}$ Repace Associates, Inc, Bowie, Maryland, USA

Correspondence to Dr Farid Shamo; shamof@michigan.gov

\section{ABSTRACT}

Objectives: To assess the effect of Michigan's smokefree air (SFA) law on the air quality inside selected restaurants and casinos. The hypothesis of the study: if the SFA law is effectively implemented in restaurants and casinos, there will be a significant reduction in the particulate matter $\mathrm{PM}_{2.5}$ measured in the same establishments after the law is implemented.

Setting: Prelaw and postlaw design study.

Participants: 78 restaurants in 14 Michigan cities from six major regions of the state, and three Detroit casinos.

Methods: We monitored the real-time $\mathrm{PM}_{2.5}$ in 78 restaurants and three Detroit casinos before the SFA law, and again monitored the same restaurants and casinos after implementation of the law, which was enacted on 1 May 2010.

\section{Primary and secondary outcome measures:}

Concentration measurements of secondhand smoke (SHS) fine particles $\left(\mathrm{PM}_{2.5}\right)$ were compared in each restaurant in the prelaw period to measurements of $\mathrm{PM}_{2.5}$ in the same restaurants during the postlaw period. A second comparison was made for $\mathrm{PM}_{2.5}$ levels in three Detroit casinos prelaw and postlaw; these casinos were exempted from the SFA law.

Results: Prelaw data indicated that $85 \%$ of the restaurants had poor to hazardous air quality, with the average venue having 'unhealthy' air according to Michigan's Air Quality Index for $\mathrm{PM}_{2.5}$. Postlaw, air quality in $93 \%$ of the restaurants improved to 'good'. The differences were statistically significant $(p<0.0001)$. By comparison, the three casinos measured had 'unhealthy' air both before and after the law.

Conclusions: The significant air quality improvement in the Michigan restaurants after implementation of the SFA law indicates that the law was very effective in reducing exposure to SHS. Since the Detroit casinos were exempted from the law, the air quality was unchanged, and remained unhealthy in both prelaw and postlaw periods.

\section{INTRODUCTION}

Secondhand smoke (SHS) contains more than 7000 chemicals. Hundreds are toxic, about 70 are known to cause cancer, and

\section{Strengths and limitations of this study}

- This study with 78 restaurant venues, the largest, single US study of its kind, adds increasing evidence to the literature supporting the risk reduction from exposure to secondhand smoke (SHS) after a smoke-free air (SFA) law was passed, demonstrating that the SFA law was successful in achieving the objective of significant reduction in the particulate matter $\mathrm{PM}_{2.5}$ measured in the same establishments before and after the law.

- The three casinos exempted from the SFA law in Detroit city continue to pose a health risk to employees and patrons, as demonstrated by the high levels of fine particle air pollution that were present before and after the SFA law went into effect.

- The annual particulate burden from SHS for fulltime employees of the three casinos was six times higher than the US Environmental Protection Agency's annual average $\mathrm{PM}_{2.5}$ standard, both before and after the SFA law was implemented, and was at the 80th percentile of all 66 US casinos previously studied.

- A limitation of this study is that a convenience sample was used to select the restaurants included in the study, introducing the potential for less objective comparisons than might occur in a random sample.

- Another limitation is that SHS is not the only source of $\mathrm{PM}_{2.5}$ particles.

many cause numerous health problems in infants and children, including severe asthma attacks, respiratory infections and ear infections. In adults, exposure to SHS causes heart disease and lung cancer. ${ }^{1}$ There is no risk-free level of exposure to SHS. Even brief exposure has immediate harmful effects on the cardiovascular system, which can increase the risk of heart attack. ${ }^{1-3}$

The hazardous health effects of exposure to SHS are well documented and established in various independent research studies and 
numerous international reports. ${ }^{1}{ }^{4}$ Scientific evidence has unequivocally established that SHS causes premature death and disease. Most of the disease burden from exposure to SHS results from cardiovascular disease, lung cancer, nasal sinus and breast cancer, as well as respiratory disease and developmental effects in children. ${ }^{14}$ Evidence also supports the association of exposure to SHS with chronic obstructive pulmonary disease. The health effects of exposure to SHS are detailed in the US Surgeon General's report. ${ }^{1}$ Exposure to SHS causes an estimated 46000 premature deaths from heart disease and 3400 deaths from lung cancer each year among non-smokers in the USA..$^{3-5}$

Research documents population-level health benefits associated with implementation of comprehensive smoke-free laws covering all public places and worksites, including bars and restaurants. These laws reduced exposure to SHS, improved the health of hospitality workers, improved indoor air quality, reduced incidence of acute myocardial infarctions and reduced incidence of asthma exacerbations. ${ }^{1}{ }^{6} 7$ However, exemptions to smoke-free laws afforded to casinos leave workers at elevated risk of heart disease and other diseases. ${ }^{8}$

The State of Michigan enacted the Dr Ron Davis Smoke Free Air (SFA) Law in 2009 (Public Act 188), and the law went into effect on 1 May 2010. The law prohibits smoking in all public places and worksites, including bars and restaurants, but has exempted three Detroit casinos. The Centers for Disease Control and Prevention recommend that states perform studies to assess indoor air quality inside hospitality venues before and after the implementation of SFA laws. ${ }^{9}$

The purpose of this study is to determine the effect of Michigan's SFA Law on the level of fine particulate matter $\leq 2.5 \mu$ in diameter $\left(\mathrm{PM}_{2.5}\right)$ in 78 restaurants in 14 cities state-wide, and in three Detroit casinos, by comparing $\mathrm{PM}_{2.5}$ prior to implementation of the SFA law with $\mathrm{PM}_{2.5}$ post-implementation of the SFA law. Prior to implementation of the law, all the 78 restaurants and three casinos allowed smoking indoors. After implementation of the law, smoking was prohibited in the 78 restaurants, but still allowed in the three casinos.

Fine particulate matter $\left(\mathrm{PM}_{2.5}\right)$ measured in numerous hospitality venues has been found to contain a substantial fraction of carcinogenic polycyclic aromatic hydrocarbons. $^{8} 1011$

The US Environmental Protection Agency (EPA) stated that scientific studies have found an association between exposure to fine particulate matter and health problems, including: aggravated asthma, chronic bronchitis, reduced lung function, heart attack and premature death in people with heart or lung disease. ${ }^{12}$

This study will answer questions concerning: (1) the concentration of the $\mathrm{PM}_{2.5}$ in 78 restaurants before and after the law, (2) whether the $\mathrm{PM}_{2.5}$ declines significantly in these restaurants after the law; and (3) if there is any significant difference in the level of $\mathrm{PM}_{2.5}$ in the three exempted Detroit casinos before and after the law.
METHODS

\section{Study design}

The Tobacco Control Program of the Michigan Department of Community Health, with assistance from local health departments and their tobacco reduction coalitions, recruited and trained field volunteers to measure the air quality in a sample of restaurants from 2005 through 2008, prior to the enactment of the Michigan SFA law. These restaurants were monitored for $\mathrm{PM}_{2.5}$ before and then again after implementation of the law for $\mathrm{PM}_{2.5}$. The volunteers were instructed to monitor the restaurants during high-volume customer visits, such as weekend evenings. The same instructions applied to the three Detroit casinos.

\section{Study sample and selection}

A sample of 78 restaurants was selected because they allowed smoking and had indoor seating. They were located in 14 Michigan cities from six distinct geographic regions of the state. The following cities participated in the study: Ann Arbor, Detroit, Flint, Grand Rapids, Kalamazoo, Lansing, East Lansing, Marquette, Midland, Novi, Saginaw, Sault Ste Marie, Traverse City and West Branch. Three casinos in the city of Detroit were selected because they are the only casinos in Michigan that were exempted by the SFA law. After the implementation of the law, the same restaurants were monitored again except one, in the city of Novi, because it was closed for remodelling. The three Detroit casinos were also monitored again.

\section{Measurement}

The concentration of respirable suspended particles $\mathrm{PM}_{2.5}$ was measured using two SidePak Personal Aerosol Monitors, Model AM510 (TSI, Minnesota, USA), which is a battery-powered lightweight photometer. The built-in sampling pump has a size-selective inlet for area measurements with a $\mathrm{PM}_{2.5}$ impactor. The SidePak AM 510 flow rates were set to $1.7 \mathrm{~L} / \mathrm{min}$ and for $1 \mathrm{~min}$ logging intervals. The SidePak was zero calibrated prior to each use by attaching a HEPA filter according to the manufacturer's specifications.

The volunteer field personnel concealed the monitors in purses, shoulder bags or backpacks. They entered the venue as paying customers, were seated and placed orders for food or beverages. They monitored air quality for at least $30 \mathrm{~min}$ in each venue. The total number of persons and the number of active smokers were recorded three times during the $30 \mathrm{~min}$ visit. The field volunteers also measured the ceiling heights and floor space of the venue using a laser ruler. They recorded times of arrival and departure for each of the venues in a field diary. These data permit calculation of smoker prevalence and smoker density, and the interpreting of results.

\section{Data analysis}

The SidePak calibration factors were set to 1 during the measurements, based on factory calibration. However, in 
Table 1 Total number of venues sampled and smoking activity

\begin{tabular}{llc}
\hline Statistics & Prelaw & Postlaw \\
\hline Venues sampled & 78 & 77 \\
Total number of persons & 2964 & 4112 \\
Total number of active smokers & 201 & 0 \\
Active smoker density & 1.11 & 0 \\
Median smoking prevalence, \% & 20 & 0 \\
\hline *Average number of burning cigarettes per 100 cubic metres.
\end{tabular}

the data analysis, a custom gravimetric calibration factor of 0.30, derived from controlled experiments, was applied to convert the logged nominal instrument readings from uncorrected milligrams per cubic metre to actual milligrams per cubic metre of fine particulate matter $\mathrm{PM}_{2.5}$ from secondhand smoke or background. ${ }^{13}$

We estimated the annual excess exposure of a full-time casino employee by using data on the average Detroit outdoor background $\mathrm{PM}_{2.5}$ exposure and our measurements of $\mathrm{PM}_{2.5}$ exposure in casinos, by assuming working times of $8 \mathrm{~h} /$ day on 250 days/year.

\section{RESULTS}

Prior to the implementation of the SFA law in Michigan, the average $\mathrm{PM}_{2.5}$ level found in the 78 restaurants was $126 \mu \mathrm{g} / \mathrm{m}^{3}$, while the average $\mathrm{PM}_{2.5}$ level in the 77 restaurants after the law was $11.8 \mu \mathrm{g} / \mathrm{m}^{3}$; this difference between prelaw and postlaw levels is statistically significant $(p<0.001)$. The summary of smoking activities inside the restaurants is shown in table 1.

There were 201 active smokers (burning cigarettes) observed before the law, while no smokers were observed

Table 2 The average $\mathrm{PM}_{2.5}$ in the restaurants of the 14 cities prelaw and postlaw in Michigan

\begin{tabular}{lll}
\hline Cities & $\begin{array}{l}\text { Prelaw } \\
\left(\mu \mathrm{g} / \mathrm{m}^{3}\right)\end{array}$ & $\begin{array}{l}\text { Postlaw } \\
\left(\mu \mathrm{g} / \mathrm{m}^{3}\right)\end{array}$ \\
\hline Grand Rapids & 103.1 & 7.5 \\
Kalamazoo & 142.6 & 10.9 \\
Lansing and East Lansing & 81 & 7.4 \\
Midland & 207 & 4.9 \\
Saginaw & 149.7 & 3.4 \\
Ann Arbor & 133 & 15.9 \\
Detroit & 78.6 & 18.7 \\
Flint & 108.6 & 15.2 \\
Novi & 178.3 & 8.8 \\
Marquette & 160.1 & 6.8 \\
Sault Ste Marie & 117.3 & 38.2 \\
Traverse City & 111.1 & 8.6 \\
West Branch & 68.9 & 6.5 \\
Minimum Value & 9 & 1.6 \\
Maximum Value & 601 & 182 \\
Mean, all (SD) & $126(109)^{*}$ & $11.8(22.9)^{*}$ \\
Median & 90.8 & 6.7 \\
Geometric mean & 88.5 & 7.4 \\
Count & 78 & 77 \\
*p Value: <0.0001. & & \\
& &
\end{tabular}

after the law because of the high compliance rate (96\%) with the SFA law. The estimated smoking prevalence in each of the 78 restaurants was calculated by multiplying the total number of active smokers for each city by three and dividing by the average number of persons observed during the measurement period. ${ }^{14-16}$ The estimated smoking prevalence in the cities ranged from $8 \%$ to $39.7 \%$ before the law. Non-smokers were in the majority in all the cities. The average smoking prevalence for the 78 restaurants was $20.3 \%$ before the law was implemented, which is similar to the adult smoking prevalence in Michigan during 2005-2006 (=22.1\%) and in 2009 $(=19.8 \%)$ when these data were collected.

Table 2 shows the average $\mathrm{PM}_{2.5}$ in 78 restaurants in 14 Michigan cities, in addition to the minimum, maximum and the measure of the central tendency.

The data are lognormally distributed; however, the arithmetic mean of the data is useful for risk assessment, while the median gives the measure of central tendency for the data, and the geometric mean characterises the fit of the data to the lognormal model. For individual cities, prelaw mean ranges from 9 to $601 \mu \mathrm{g} / \mathrm{m}^{3}$ with an average of $126 \mu \mathrm{g} / \mathrm{m}^{3}$. By contrast, the postlaw mean ranges from 1.6 to $182 \mu \mathrm{g} / \mathrm{m}^{3}$ with an average of $11.8 \mu \mathrm{g} / \mathrm{m}^{3}$. The outdoor air quality in Michigan during 2007-2011, measured using the US EPA Federal Reference Method, spanned a much smaller range, from 10 to $18 \mu \mathrm{g} / \mathrm{m}^{3}$, and all measures of central tendency were around $12 \mu \mathrm{g} / \mathrm{m}^{3}$. It appears that the postlaw indoor (of the 77 restaurants) and outdoor $\mathrm{PM}_{2.5}$ levels are nearly identical, indicating little or no effect from cooking. The prelaw indoor level of $\mathrm{PM}_{2.5}$ in the 78 restaurants was 10.5 times higher than the outdoor levels for Michigan $\left(12 \mu \mathrm{g} / \mathrm{m}^{3}\right)$, the threshold for good outdoor air quality according to the EPA National Ambient Air Quality Standard (NAAQS) of $12 \mu \mathrm{g} / \mathrm{m}^{3}{ }^{3}{ }^{17}$

The average $\mathrm{PM}_{2.5}$ level for the casinos was $92 \mu \mathrm{g} / \mathrm{m}^{3}$ prior to the law and $86 \mu \mathrm{g} / \mathrm{m}^{3}$ after the law took effect; this difference was not statistically significant. Figure 1 shows the $\mathrm{PM}_{2.5}$ frequency distributions for the three casinos and the 78 restaurants prelaw and postlaw using the Michigan Air Quality Index (AQI) descriptors, from 'good' to 'hazardous'. The prelaw averages are represented by the colour red, while the postlaw averages are indicated by blue.

The average annual $\mathrm{PM}_{2.5}$ exposure for a full-time employee in the three casinos was $28.9 \mu \mathrm{g} / \mathrm{m}^{3}$. This level exceeds the $12 \mu \mathrm{g} / \mathrm{m}^{3}$ EPA NAAQS by 2.4 times. ${ }^{17}$ We calculated this level by assuming that during the workday, the worker is exposed to $(250 \mathrm{~d})(8 \mathrm{~h} / \mathrm{d})$ $\left(86 \mu \mathrm{g} / \mathrm{m}^{3}\right)=172000 \mu \mathrm{g}-\mathrm{h} / \mathrm{m}^{3}$; the same employee is exposed only to background particle levels of $12 \mu \mathrm{g} / \mathrm{m}^{3}$ for $16 \mathrm{~h} / \mathrm{d}$ during non-work times. Then the worker's background exposure during the workday is $(250 \mathrm{~d})$ $(16 \mathrm{~h} / \mathrm{d})\left(12 \mu \mathrm{g} / \mathrm{m}^{3}\right)=48000 \mu \mathrm{g}-\mathrm{h} / \mathrm{m}^{3}$, for a total work exposure of $220000 \mu \mathrm{g}-\mathrm{h} / \mathrm{m}^{3}$ during the year. Then for the remaining 115 days, to background only, yielding an additional exposure of ( 115 days) $(24 \mathrm{~h} /$ day $)\left(12 \mu \mathrm{g} / \mathrm{m}^{3}\right)$ $=33120 \mu \mathrm{g}-\mathrm{h} / \mathrm{m}^{3}$. Therefore, the average annual $\mathrm{PM}_{2.5}$ 
Figure $1 \mathrm{PM}_{2.5}$ frequency distributions for 3 Detroit casinos and 78 restaurants vs Michigan Air Quality Index. The red points indicate prelaw measurements, while blue points indicate postlaw measurements.

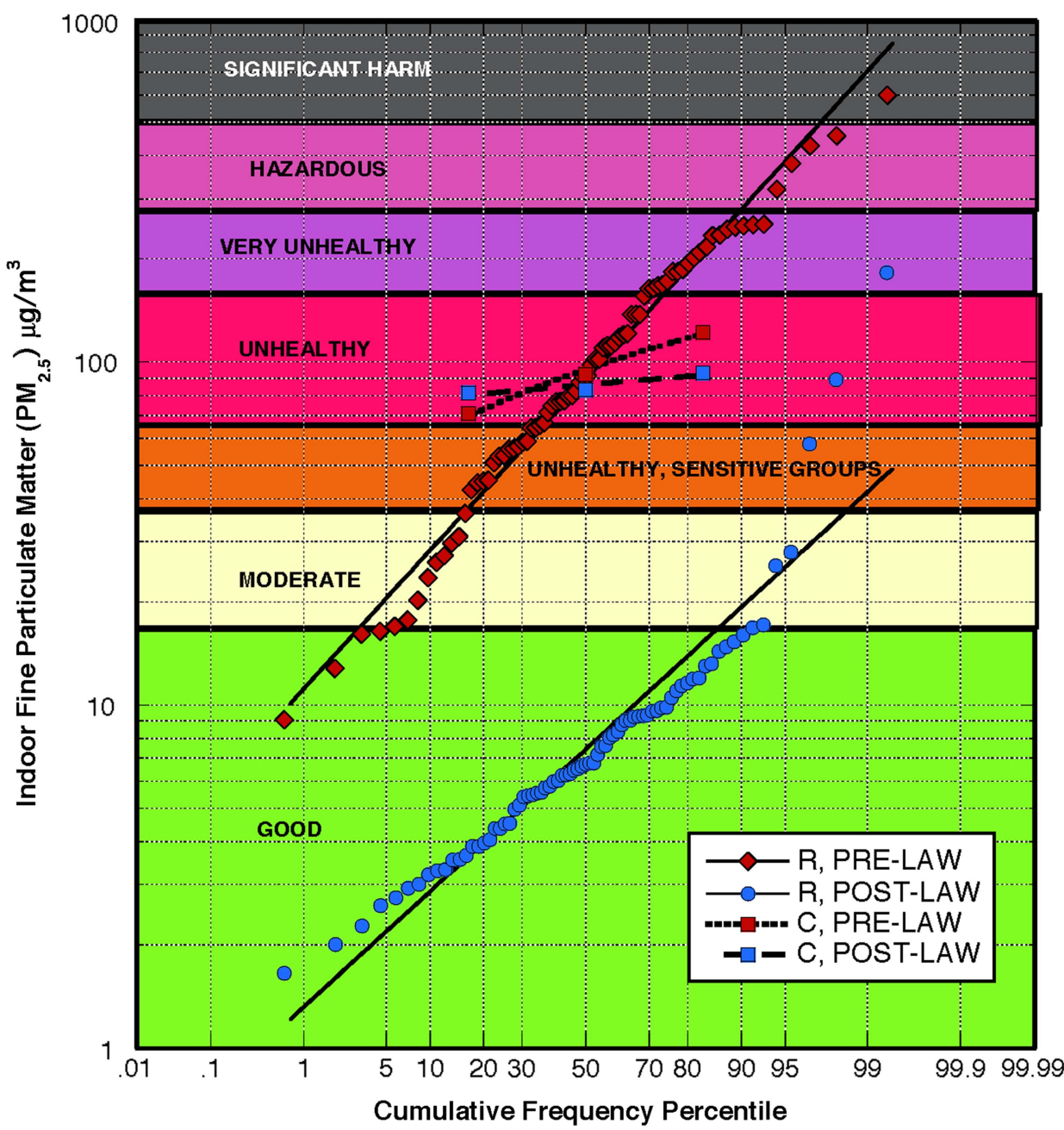

exposure for a full-time employee in any one of the three casinos is $\left(172000 \mu \mathrm{g}-\mathrm{h} / \mathrm{m}^{3}+48000 \mu \mathrm{g}-\mathrm{h} / \mathrm{m}^{3}+33\right.$ $120 \mu \mathrm{g}-\mathrm{h} / \mathrm{m}^{3}$ ) $=253120 \mu \mathrm{g}-\mathrm{h} / \mathrm{m}^{3}$ per year. However, if the casinos had not been exempted from the ban, the worker's exposure would have been just (365 days) (24 h/day) $\left(12 \mu \mathrm{g} / \mathrm{m}^{3}\right)=105120 \mu \mathrm{g}-\mathrm{h} / \mathrm{m}^{3}$. Thus, the average casino worker's exposure to $\mathrm{PM}_{2.5}$ air pollution has been increased by a factor of (253 120/105 120)= (2.4).

Figure 1 shows that more than $85 \%$ of the restaurants had unhealthy air prior to enactment of the smoke-free law, while less than $5 \%$ had unhealthy air afterwards.

Table $3 \mathrm{PM}_{2.5}$ measurements in the three Detroit casinos

\begin{tabular}{llll}
\hline Statistics & $\begin{array}{l}\text { Prelaw } \\
\left(\mu \mathbf{g} / \mathbf{m}^{\mathbf{3}}\right)\end{array}$ & $\begin{array}{l}\text { Postlaw } \\
\left(\boldsymbol{\mu g} / \mathbf{m}^{\mathbf{3}}\right)\end{array}$ & $\mathbf{p ~ V a l u e}$ \\
\hline Minimum & 6.6 & 23.1 & - \\
Maximum & 193 & 281 & - \\
Mean & 92 & 85.7 & 0.52 \\
Median & 94.2 & 85.7 & - \\
SD & $(25.8)$ & $(6.19)$ & - \\
Geometric & 92.6 & 85.6 & - \\
Mean & & & \\
\hline
\end{tabular}

For the three Detroit casinos, the same monitoring protocol was used; the SidePak real-time fine particle monitors were deployed by a team of two field volunteers who visited the same three casinos before and after the implementation of the Michigan smoke-free law. Unlike the restaurants and as mentioned, the Detroit casinos were exempted from the law by the state legislature. The $\mathrm{PM}_{2.5}$ was measured on Saturday evenings, prelaw on 18 April 2009, and postlaw on 14 May 2011. Table 3 shows the $\mathrm{PM}_{2.5}$ measurements in the three Detroit casinos. As shown in table 3, the mean $\mathrm{PM}_{2.5}$ was $92 \mu \mathrm{g} / \mathrm{m}^{3}$ before the law and $85.7 \mu \mathrm{g} / \mathrm{m}^{3}$ after the law went into effect. Figure 1 shows three readings in red-coloured points before the law and other three readings in blue-coloured points after the law.

The average $\mathrm{PM}_{2.5}$ level in 78 restaurants before the implementation of the SFA law was $126 \mu \mathrm{g} / \mathrm{m}^{3}$. The level was five times higher than the WHO guideline level for $24 \mathrm{~h}$ exposure of $25 \mu \mathrm{g} / \mathrm{m}^{3}$ (WHO, 2006). The level was also 3.6 times higher than the health-based $24 \mathrm{~h}$ National Ambient Air Quality Standard (NAAQS) for outdoor air average of $35 \mu \mathrm{g} / \mathrm{m}^{3}$ set by the US EPA on 14 December 2012 . $^{17}$

Indoor air quality in 77 restaurants was significantly improved and $\mathrm{PM}_{2.5}$ average level was reduced by $90.6 \%$

\section{DISCUSSION}


after the implementation of the Michigan SFA law. The average postlaw indoor $\mathrm{PM}_{2.5}$ level of $11.8 \mu \mathrm{g} / \mathrm{m}^{3}$ was below both WHO guideline and the NAAQS. Compliance with SFA law is critical to achieving the goal of eliminating exposure to SHS. All restaurants measured in this study complied with the SFA law. The findings in this study indicate that a state-wide law to eliminate smoking in enclosed workplaces and public places substantially reduced $\mathrm{PM}_{2.5}$ levels in all monitored Michigan restaurants, changing the air quality from unhealthy to good.

Effects of comprehensive SFA laws on indoor air quality and public health are clear. However, opponents of smoke-free regulations compromise the health of casino workers by enacting exemptions from the SFA law for the three Detroit casinos. The data for indoor air quality in these casinos clearly indicate unhealthy air before and after the implementation of the law (as shown in figure 1).

Similar results were found in a cross-sectional study of 53 hospitality venues in seven major cities across the USA; this study showed $82 \%$ less indoor air pollution in the locations subject to SFA laws while in our study we found $90.6 \%$ reduction. ${ }^{18}$ Lee et $a l^{19}$ found $88 \%$ decline in the mean indoor $\mathrm{PM}_{2.5}$ in hospitality venues after the implementation of the comprehensive SFA law in the State of Kentucky; the indoor $\mathrm{PM}_{2.5}$ was significantly reduced from 161 to $20 \mu \mathrm{g} / \mathrm{m}^{3}$. Repace et al measured the air quality in seven Boston, Massachusetts, pubs before and after Boston's smoke-free law, and found that presmoking-ban $\mathrm{PM}_{2.5}$ levels in those pubs averaged $179 \mu \mathrm{g} / \mathrm{m}^{3}, 23$ times higher than postban levels, which averaged $7.7 \mu \mathrm{g} / \mathrm{m}^{3}$. The presmoking ban levels of fine particle air pollution in all the pubs were in the unhealthy to hazardous range of the AQI. Postban air pollution measurements showed $95 \%$ reductions in $\mathrm{PM}_{2.5}$ levels. ${ }^{20} \mathrm{~A}$ study of changes in indoor air quality in 20 hospitality venues in western New York before and after a state-wide clean indoor air law, showed a postlaw decrease of $84 \%$ in average $\mathrm{PM}_{2.5}$ levels. ${ }^{21}$ Repace studied eight hospitality venues, including one casino in Delaware before and after Delaware's comprehensive smoking ban, and found that levels of $\mathrm{PM}_{2.5}$ decreased by $90 \%$ as a result of the smoking ban. ${ }^{22}$ Jiang et $a l^{13}$ found, in their study measuring the fine particles and smoking activity in a state-wide survey of 36 California Indian casinos, that the average $\mathrm{PM}_{2.5}$ was $63 \mu \mathrm{g} / \mathrm{m}^{3}$.

By contrast, Repace ${ }^{23}$ measured an average $\mathrm{PM}_{2.5}$ of $106 \mu \mathrm{g} / \mathrm{m}^{3}$ higher in a study of three Pennsylvania casinos.

Other studies have directly assessed the effects of SHS exposure on human health. Rapid improvements in the respiratory health of bartenders were seen after California State's SFA law was implemented. ${ }^{24}$ In Michigan, Wilson et $a l^{25}$ found a significant improvement in the six selfreported respiratory symptoms of bartenders, plus a significant reduction in the mean urinary cotinine and 4(methylnitrosamino)-1-(3-pyridyl)-1-butanol (NNAL) levels, 2 months after the implementation of the smoke- free law. Farrelly $e t a l^{26}$ also showed a significant decrease in both salivary cotinine concentrations and sensory symptoms in hospitality workers after New York State's SFA law prohibited smoking in worksites.

A Scottish study of the health impact of the smoking ban on bar workers, found significant early improvements in symptoms, spirometry measurements and systemic inflammation of bar workers. Asthmatic bar workers also had reduced airway inflammation and improved quality of life after the implementation of Scotland's smoke-free legislation in 2006 . $^{27}$

Chronically increased exposure to outdoor $\mathrm{PM}_{2.5}$ is associated with significant increases in heart disease mortality in the general population. ${ }^{28}$ Pope $e t a t^{29}$ concluded that relatively low levels of $\mathrm{PM}_{2.5}$ from either ambient air pollution or SHS are sufficient to increase cardiovascular disease mortality risk. Quantitative estimates of ambient $\mathrm{PM}_{2.5}$ exposure-response and mortality indicate that a daily increase of $10 \mu \mathrm{g} / \mathrm{m}^{3}$ in outdoor $\mathrm{PM}_{2.5}$ concentrations increases the risk of ischaemic heart disease (IHD) mortality (ICD 10 codes I20-I25) in non-smokers by an average of 18-28\% over time to scales ranging from 1 to 18 years (Pope et al). Applying this exposure-response relationship to the exempted casino workers' exposure yields, an estimated increase in daily exposure of $\left(\left(12 \mu \mathrm{g} / \mathrm{m}^{3}\right)(2.4)-\right.$ $\left.12 \mu \mathrm{g} / \mathrm{m}^{3}\right)=16.8 \mu \mathrm{g} / \mathrm{m}^{3}$, for an estimated increase in IHD risk of $\left(16.8 \mu \mathrm{g} / \mathrm{m}^{3} / 10 \mu \mathrm{g} / \mathrm{m}^{3}\right)(18-28 \%)=30-47 \%$.

A notable limitation of this study is the fact that a convenience sample was used to select the restaurants included in the study, thus introducing the potential for less objective comparisons than might have occurred in a random sample. Other limitations are that SHS is not the only source of $\mathrm{PM}_{2.5}$ particles and the inability to control for other variables such as ambient particle smoke from cooking, and the presence of table candles. This explains why one out of the six restaurants in Sault Ste Marie city had a high postban concentration of $182 \mu \mathrm{g} / \mathrm{m}^{3}$, as they had oil candles and were using a smoky grill inside the restaurant during the monitoring process.

\section{CONCLUSIONS}

This study, the largest single US study of its kind, demonstrates that air quality in Michigan restaurants prior to the SFA law had unhealthy to hazardous levels of indoor air pollution resulting from indoor smoking. The comprehensive SFA law, implemented on 1 May 2010, that prohibited smoking in all public places and places of employment has been shown to decrease exposure to toxic $\mathrm{PM}_{2.5}$ by $90.6 \%$, and yielded good air quality, as shown in figure 1 . However, the three Detroit casinos exempted from the SFA law continue to pose a health risk, as demonstrated by the unhealthy levels of fine particle air pollution both before and after the law went into effect. After passing the SFA law, the casino's workers and patrons remained exposed to dangerous air pollution levels. ${ }^{8}$ In light of the evidence that there is no risk-free level of exposure to SHS, the only safe and 
proven way to reduce the exposure to these toxic particulates from SHS is by enacting a comprehensive SFA law, without any exemptions, to ensure adequate protection of the health of employees and patrons. ${ }^{130}$

Acknowledgements The authors would like to thank the local health department staff, coalition members and the volunteers who assisted us in monitoring the restaurants and the casinos, before and after the implementation of the SFA law. We would also like to thank Mikelle Robinson, who was the state tobacco control programme manager at the time of conducting this study for her great support to this study.

Contributors FS: Planned the concept and design of the study, drafted the protocol, performed the sample selection, analysis and interpretation of the data, and drafted and submitted the manuscript. TW: Participated in planning of the study, and followed up with data collection, administrative and logistic support, final approval of the article and revision of the manuscript. JK: Participated in planning of the study, and followed up with data collection, obtaining the funding and revision of the manuscript. JR: Participated in planning of the study, revision of protocol, revision of the survey, data collection, entry and analysis, and revision of the manuscript.

Funding This study was supported, in part, by cooperative agreements from CDC's Communities Putting Prevention to Work programme (3U58DP001973-01S2)

Competing interests None declared.

Ethics approval Michigan Department of Community Health Institutional Review Board.

Provenance and peer review Not commissioned; externally peer reviewed.

Data sharing statement No additional data are available.

Open Access This is an Open Access article distributed in accordance with the Creative Commons Attribution Non Commercial (CC BY-NC 4.0) license, which permits others to distribute, remix, adapt, build upon this work noncommercially, and license their derivative works on different terms, provided the original work is properly cited and the use is non-commercial. See: http:// creativecommons.org/licenses/by-nc/4.0/

\section{REFERENCES}

1. U.S. Department of Health and Human Services. The health consequences of involuntary exposure to tobacco smoke: a report of the surgeon general. Atlanta, GA: U.S. Department of Health and Human Services, Centers for Disease Control and Prevention, National Center for Chronic Disease Prevention and Health Promotion, Office on Smoking and Health, 2006.

2. U.S. Department of Health and Human Services. A report of the surgeon general: how tobacco smoke causes disease: what it means to you. Atlanta: U.S. Department of Health and Human Services, Centers for Disease Control and Prevention, National Center for Chronic Disease Prevention and Health Promotion, Office on Smoking and Health, 2010.

3. Institute of Medicine. Secondhand smoke exposure and cardiovascular effects: making sense of the evidence. Washington: National Academy of Sciences, Institute of Medicine, 2009.

4. California Environmental Protection Agency. Proposed identification of environmental tobacco smoke as a toxic air contaminant, part B: Health effects. Sacramento, CA: State of California Office of Environmental Health Hazard Assessment, 2005.

5. Centers for Disease Control and Prevention. Smoking-attributable mortality, years of potential life lost, and productivity losses-United States, 2000-2004. MMWR Morb Mortal Wkly Rep 2008;57:1226-8.

6. Callinan JE, Clarke A, Doherty $\mathrm{K}$, et al. Legislative smoking bans for reducing secondhand smoke exposure, smoking prevalence and tobacco consumption. Cochrane Database Syst Rev 2010;(4): CD005992.

7. Hahn EJ. Smokefree legislation: A review of health and economic outcomes research. AM J Prev Med 2010;39(6 Suppl 1):S66-76.
8. Repace JL, Jiang RT, Cheng KC, et al. Fine particle and secondhand smoke air pollution exposures and risks inside 66 US casinos. Environ Res 2011;111:473-84.

9. Centers of Disease Control and Prevention. Evaluation toolkit for smoke-free policies. Atlanta: U.S. Department of Health and Human Services, 2008.

10. Surgeon general's report-how tobacco smoke causes disease: the biology and behavioral basis for smoking-attributable disease. Rockville, MD: U.S. Department of Health and Human Services. Public Health Services. Office of Surgeon General, 2010.

11. Hoffmann D, Hoffmann I. Chemistry and Toxicology, in Smoking and Tobacco Control Monograph 9. Cigars: Health Effects and Trends. Bethesda, MD: National Institutes of Health, National Cancer Institute, 1998

12. U.S. EPA, Fine Particle (PM2.5) Designations, Basic Information. http://www.epa.gov/airquality/particulatematter/designations/ basicinfo.htm

13. Jiang RT, Cheng KC, Acevedo-Bolton V, et al. Measurement of fine particles and smoking activity in a statewide survey of 36 California Indian casinos. J Expo Sci Environ Epidemiol 2011;21:31-41. (open access). http://www.nature.com/jes/journal/vaop/ncurrent/abs/ jes200975a.html http://dx.doi.org/10.1038/jes.2009.75

14. Repace JL. Exposure to secondhand smoke. In: Ott W, Steinemann A, Wallace L, eds. Exposure analysis. Boca Raton, FL: CRC Press, 2007. Chapter 9

15. Pritsos CA, Pritsos KL, Spears KE. Smoking rates among gamblers at Nevada casinos mirror US smoking rate. Tob Control 2008;17:82-5.

16. Repace JL, Lowrey AH. Indoor air pollution, tobacco smoke, and public health. Science 1980;208:464-72.

17. U.S. Environmental Protection Agency. EPA's revised air quality standards for particle pollution: monitoring, designations and permitting requirements. 2013. http://www.epa.gov/pm/2012/ decfsimp.pdf

18. Travers MJ, Hyland A, Repace JL. 7-City Air Monitoring Study (7-CAMS), March-April 2004. Buffalo: Roswell Park Cancer Institute, 2004.

19. Lee K, Hahn EJ, Robertson HE, et al. Strength of smoke-free laws and indoor air quality. Nicotine Tob Res 2009;11:381-6.

20. Repace JL, Hyde JN, Brugge D. Air pollution in Boston bars before and after a smoking ban. BMC Public Health 2006;6:266.

21. Centers for Disease Control and Prevention (CDC). Indoor air quality in hospitality venues before and after the implementation of a clean indoor air law-Western New York, 2003. MMWR Morb Mortal Wkly Rep 2004:53:1038-41.

22. Repace JL. Respirable particles and carcinogens in the air of Delaware hospitality venues before and after a smoking ban. J Occup Environ Med 2004:46:887-905

23. Repace JL. Secondhand smoke in Pennsylvania casinos: a study of nonsmokers' exposure, dose, and risk. Am J Public Health 2009;99:1478-85.

24. Eisner MD, Smith AK, Blanc PD. Bartenders' respiratory health after establishment of smoke-free bars and taverns. JAMA 1998;280:1909-14.

25. Wilson T, Shamo F, Boynton K, et al. The impact of Michigan's Dr. Ron Davis smoke-free air law on levels of cotinine, tobacco-specific lung carcinogen and severity of self-reported respiratory symptoms among non-smoking bar employees. Tob Control 2012;21:593-5.

26. Farrelly MC, Nonnemaker JM, Chou R, et al. Changes in hospitality workers' exposure to secondhand smoke following the implementation of New York's smoke-free law. Tob Control 2005;14:236-41.

27. Menzies D, Nair A, Williamson PA, et al. Respiratory symptoms, pulmonary function, and markers of inflammation among bar workers before and after a legislative ban on smoking in public places. JAMA 2006;296:1742-8.

28. Pope CA III, Dockery DW. Health effects of fine particulate air pollution lines that connect. J Air Waste Manag Assoc 2006;56:709-42.

29. Pope CA III, Burnett RT, Krewski D, et al. Cardiovascular mortality and exposure to airborne fine particulate matter and cigarette smoke: shape of the exposure-response relationship. Circulation 2009;120:941-8.

30. WHO Framework Convention on Tobacco Control. Guidelines on protection from exposure to tobacco smoke. Article 8 of the FCTC. Geneva, Switzerland: WHO Framework Convention on Tobacco Control, 2007. 